\title{
Paracrine Effects of Bone Marrow Mononuclear Cells in Survival and Cytokine Expression after 90\% Partial Hepatectomy
}

\author{
Carlos Oscar Kieling, ${ }^{1,2}$ Carolina Uribe-Cruz, ${ }^{1,2,3}$ Mónica Luján López, \\ Alessandro Bersch Osvaldt, ${ }^{5}$ Themis Reverbel da Silveira, ${ }^{1,2}$ and Ursula Matte ${ }^{3,4,6}$ \\ ${ }^{1}$ Experimental Laboratory of Gastroenterology and Hepatology, HCPA, Ramiro Barcelos 2350, 90035-903 Porto Alegre, RS, Brazil \\ ${ }^{2}$ Post-Graduation Program on Medicine: Sciences in Gastroenterology, UFRGS, Ramiro Barcelos 2350, \\ 90035-903 Porto Alegre, RS, Brazil \\ ${ }^{3}$ Gene Therapy Center, HCPA, Ramiro Barcelos 2350, 90035-903 Porto Alegre, RS, Brazil \\ ${ }^{4}$ Post-Graduation Program on Genetics and Molecular Biology, UFRGS, Av. Bento Gonçalves 9500, 91501-970 Porto Alegre, RS, Brazil \\ ${ }^{5}$ Post-Graduation Program in Surgery, UFRGS, Ramiro Barcelos 2350, 90035-903 Porto Alegre, RS, Brazil \\ ${ }^{6}$ Post-Graduation Program in Child and Adolescent Health, UFRGS, Ramiro Barcelos 2350, 90035-903 Porto Alegre, RS, Brazil
}

Correspondence should be addressed to Ursula Matte; umatte@hcpa.edu.br

Received 23 September 2016; Revised 30 November 2016; Accepted 10 January 2017; Published 23 February 2017

Academic Editor: Dario Coletti

Copyright (C) 2017 Carlos Oscar Kieling et al. This is an open access article distributed under the Creative Commons Attribution License, which permits unrestricted use, distribution, and reproduction in any medium, provided the original work is properly cited.

Acute liver failure is a complex and fatal disease. Cell-based therapies are a promising alternative therapeutic approach for liver failure due to relatively simple technique and lower cost. The use of semipermeable microcapsules has become an interesting tool for evaluating paracrine effects in vivo. In this study, we aimed to assess the paracrine effects of bone marrow mononuclear cells (BMMC) encapsulated in sodium alginate to treat acute liver failure in an animal model of $90 \%$ partial hepatectomy (90\% $\mathrm{PH})$. Encapsulated BMMC were able to increase 10-day survival without enhancing liver regeneration markers. Gene expression of $\mathrm{Il}-6$ and $\mathrm{Il}-10$ in the remnant liver was markedly reduced at $6 \mathrm{~h}$ after $90 \% \mathrm{PH}$ in animals receiving encapsulated BMMC compared to controls. This difference, however, was neither reflected by changes in the number of CD68+ cells nor by serum levels of IL6. On the other hand, treated animals presented increased caspase activity and gene expression in the liver. Taken together, these results suggest that BMMC regulate immune response and promote apoptosis in the liver after $90 \% \mathrm{PH}$ by paracrine factors. These changes ultimately may be related to the higher survival observed in treated animals, suggesting that BMMC may be a promising alternative to treat acute liver failure.

\section{Introduction}

Acute liver failure is a complex and fatal disease, characterized by jaundice, coagulopathy, and hepatic encephalopathy [1]. The etiology varies from viral hepatitis, drug-induced hepatotoxicity, and metabolic liver disease to uncertain causes $[1,2]$. Liver transplantation remains the only proven treatment for end-stage liver failure but is limited by the availability of donor organs $[1,3]$.

Cell-based therapies are a promising alternative therapeutic approach for liver failure due to relatively simple technique and lower cost $[3,4]$. Several preclinical and clinical experiments have been reported on the safety and efficacy of bone-marrow-derived mononuclear cells to treat liver disorders [5-8].

Recently, one of the best studied mechanisms of action for these cells is the release of paracrine factors cells [9]. However, the pathway in which they act has still not been fully clarified mainly by the difficulty of in vivo studies. The use of semipermeable microcapsules has become an interesting tool for evaluating paracrine effects in vivo. These microcapsules can immune-isolate xenogeneic cells allowing the exchange of low-molecular-weight nutrients and oxygen across the membranes [10]. In this study, we aimed to 
assess the paracrine effect of bone marrow mononuclear cells (BMMC) encapsulated in sodium alginate to treat acute liver failure in an animal model of $90 \%$ partial hepatectomy.

\section{Materials and Methods}

2.1. Animals. Two-month-old male Wistar rats $(298 \pm 60 \mathrm{~g})$ were kept under controlled temperature (between 18 and $22^{\circ} \mathrm{C}$ ) in $12 \mathrm{~h}$ light-dark cycles with free access to water and standard chow at Experimental Animal Unit at Hospital de Clínicas de Porto Alegre (HCPA). Handling, care, and processing of animals were carried out according to regulations approved by our local Ethics Committee and complied with the National Guidelines on Animal Care.

2.2. Experimental Design. Rats were randomly divided into two groups. Treated group received encapsulated bone marrow mononuclear cells (BMMC, $n=39$ ) and control group $(n=41)$ received empty capsules (EC). Survival was observed for up to 10 days after $90 \% \mathrm{PH}$.

To evaluate the early effects of treatments an additional set of animals were randomly divided into two groups (BMMC and EC) and euthanized at 6, 12, 24, 48, and 72 hours after $90 \% \mathrm{PH}$ ( $n=6-8 /$ group/time point). For mononuclear bone marrow cells 5 animals were used as donors and another 5 animals without liver injury were used as normal controls.

2.3. Isolation of BMMC. Five naïve male Wistar rats were used as BMMC donors as described by Matte et al. [11]. Briefly, in a sterile environment, the femurs and tibias were isolated and whole bone marrow was flushed with complete medium: DMEM (Dulbecco's Modified Eagle Medium, LGC, Brazil) supplemented with $10 \%$ fetal bovine serum (Gibco, USA), $1 \%$ penicillin/streptomycin (Gibco, USA) and centrifuged at $800 \mathrm{~g}$ for 5 minutes. The pellet was diluted in complete medium and then placed onto a Ficoll Histopaque (GE-Healthcare, USA) layer and centrifuged at $800 \mathrm{~g}$ for $30 \mathrm{~min}$. The interface was separated using a pipette, and cells were rinsed with PBS three times. Cells were counted using the Neubauer chamber and Trypan Blue exclusion test to verify cell viability.

2.4. Cell Encapsulation. Cell encapsulation was performed according to our laboratory protocol, previously described [12]. Briefly, BMMC were mixed with $1.5 \%$ sodium alginate (Sigma-Aldrich, USA) in complete medium and extruded through a Encapsulation Unit, type J1 (Nisco, Switzerland), attached to JMS Syringe Pump. Droplets were sheared off with an air flow of $5 \mathrm{~L} / \mathrm{min}$ delivered to the tip of a $27 \mathrm{G}$ needle and the rate of infusion was $40 \mathrm{~mL} / \mathrm{h}$. The droplets fell into a bath of $125 \mathrm{mM} \mathrm{CaCl}$ and ionically cross-linked with $\mathrm{Ca}_{2}{ }^{+}$to form solid spherical hydrogel beads containing embedded BMMC. In each well capsules were produced from a volume of $2 \mathrm{~mL}$ of alginate suspension, containing $1 \times 10^{6}$ $\mathrm{BMMC/animal.} \mathrm{BMMC} \mathrm{encapsulation} \mathrm{was} \mathrm{carried} \mathrm{out} \mathrm{under}$ sterile conditions. For control group, $2 \mathrm{~mL}$ of empty capsules was produced using the same approach, although without cells. The resulting capsules were maintained under normal cell culture conditions with complete medium at $37^{\circ} \mathrm{C}$ and $5 \%$ $\mathrm{CO}_{2}$ for $24 \mathrm{~h}$ prior to administration.

2.5. Animal Model of $90 \%$ Partial Hepatectomy and Capsules Transplantation. Hepatectomy was carried out under isoflurane (Forane ${ }^{\circledR}$, Abbott SA, Argentina) anesthesia [13]. An abdominal midline incision was made to expose the liver. Ninety percent hepatectomy was performed by a single operator as described by Gaub and Iversen (1984) [14]. In brief, the left lateral (30\%), left median (40\%), and right superior lobes $(20 \%)$ were removed, leaving only the caudate lobes. Immediately after $90 \% \mathrm{PH}$, as well as before complete suture, microcapsules (either empty or containing BMMC) were placed into the peritoneal cavity and glucose was supplemented i.p. ( $5 \%$ of body weight). The incision was then closed. After the rats recovered from anesthesia, animals were given i.p. glucose (5\% of body weight) until day seven and received $20 \%$ glucose in their drinking water and standard chow ad libitum until euthanasia.

2.6. Euthanasia. Euthanasia was performed in $\mathrm{CO}_{2}$ chambers at the $6,12,24,48$, and $72 \mathrm{~h}$ or at 10 days after $90 \%$ $\mathrm{PH}$. Immediately after euthanasia blood was collected and the serum was kept at $-80^{\circ} \mathrm{C}$ until analysis; the liver was removed and weighed and part was flash-frozen in liquid nitrogen and the rest was placed in $10 \%$ buffered formalin. At each time point and every day until day 10 animals were weighed.

2.7. Liver Regeneration Rate. The liver regeneration rate [15] was calculated as follows: liver regeneration rate $(\%)=100 \times$ $[C-(A-B)] / A$, where $A$ is the estimated liver weight before $\mathrm{PH}, B$ is the excised liver weight at the time of $\mathrm{PH}$, and $C$ is the weight of the regenerated liver at the time of euthanasia.

2.8. Histology and Immunohistochemistry. Paraffin-embedded liver specimens were cut in $4 \mu \mathrm{m}$ sections and stained with hematoxylin and eosin (H-E). Mitotic index was performed by counting the number of hepatocytes undergoing mitosis in 10 high power fields (HPF) at each time point until $72 \mathrm{~h}$ after $90 \% \mathrm{PH}[6]$.

To assess the rate of hepatocyte proliferation, the number of hepatocytes undergoing mitosis was counted in $10 \mathrm{HPF}$. In addition, 5-bromo- $2^{\prime}$-deoxyuridine (BrdU) immunostaining was done using BrdU staining kit (Invitrogen, USA). Two hours before sacrifice, rats ( $n=3$ /group) were injected with $\mathrm{BrdU}(1 \mathrm{~mL} / \mathrm{g})$. Thereafter, liver sections were incubated with BrdU antibody and the number of positive hepatocytes was counted in $5 \mathrm{HPF}$.

2.9. Serum Cytokine Levels. Serum level of IL-6 was quantified by enzyme-linked immunosorbent assay (ELISA) using commercial kits (R\&D Systems ${ }^{\circledR}$, Minneapolis, Minnesota, EUA) in accordance with the manufacturer's instructions.

2.10. Quantitative Real-Time PCR. Total RNA was extracted from liver tissue $(\sim 50 \mathrm{mg})$ using TRIzol reagent (Invitrogen, USA) according to the manufacturer's instructions and $2 \mu \mathrm{g}$ was reverse-transcribed using High Capacity cDNA Reverse 
Transcription Kit (Life Technologies, USA). The expression of genes involved in inflammation pathway (Interleukins 6 and 10) and apoptosis (Caspase 3 ) were measured using TaqMan ${ }^{\circledR}$ assays (Life Technologies, USA). The percentage of a test RNA to that of $\beta$-actin was calculated by subtracting the cycle to reach the threshold (CT) for that gene from the CT for $\beta$-actin to determine the $\Delta \mathrm{CT}$, and the formula is percent $\beta$-actin $=$ $(100) \times 2 \Delta \mathrm{CT}$ [12]. The percent $\beta$-actin for hepatectomized animals was divided by the percent $\beta$-actin in normal animals to determine the ratio of gene expression in both treatments after $90 \% \mathrm{PH}$ to normal rats. Livers of animals without injury were used as calibrator group (normal values $=1$ ).

2.11. Immunohistochemistry Analysis. Paraffin-embedded liver specimens were cut in $4 \mu \mathrm{m}$ sections and Kupffer cells were quantified by immunostaining for CD68. For that, liver sections were incubated overnight at $4^{\circ} \mathrm{C}$ with the primary antibody rabbit IgG-CD68 (1:800, Abcam, USA) and washed with phosphate buffer Tween 20; then universal biotinylated link and streptavidin-HRP were added (Dako, USA) and revealed with DAB kit (Dako, USA). The slides were counterstained with hematoxylin. The number of $\mathrm{CD} 68^{+}$cells was counted in 5 randomly selected HPF $(\times 400)$ per slide.

2.12. Caspase 3 Activity. Fluorometric Caspase 3 activity (Sigma-Aldrich, USA) assays were performed according to the manufacturer's instructions. Briefly, $15 \mu \mathrm{L}$ of liver homogenate in PBS was placed in an opaque 96-well plate and $200 \mu \mathrm{L}$ of mixture reaction solution (containing AcetylAsp-Glu-Val-Asp-7-amido-4-methylcoumarin) was added to each well. The plate was incubated in dark at $25^{\circ} \mathrm{C}$ and every 10 minutes the fluorescence was read at $360 \mathrm{~nm}$ of excitation and 460 of emission. Caspase activity was normalized by protein measured by Lowry method [16].

2.13. Statistical Analysis. Results were expressed as means \pm standard deviation (SD) or medians when required. Statistical differences were assessed by Student's $t$-test and for nonparametric variables Mann-Whitney test was used. The survival rate was analyzed by Kaplan-Meier curve. The comparison of survival rates in different groups was tested by the log rank test. $P$ values less than 0.05 were considered statistically significant.

\section{Results}

3.1. BMMC Increase Survival Rate in Rats with $90 \%$ Partial Hepatectomy. Survival rate was accompanied during 10 days after $90 \% \mathrm{PH}$. The survival rate in BMMC group was higher (54.5\%) than EC group (5\%; $P=0.003$; Figure 1). Interestingly, the peak of death in BMMC group occurred within the first three days after PH. In contrast, animals in EC group died over time. Thus, the next analyses were performed until 72 hours after $90 \% \mathrm{PH}$ to address the beneficial effect of encapsulated BMMC.

3.2. BMMC Do Not Enhance Liver Regeneration. To address if the increase of survival rate in BMMC was a consequence of a higher liver regeneration, we calculated liver regeneration

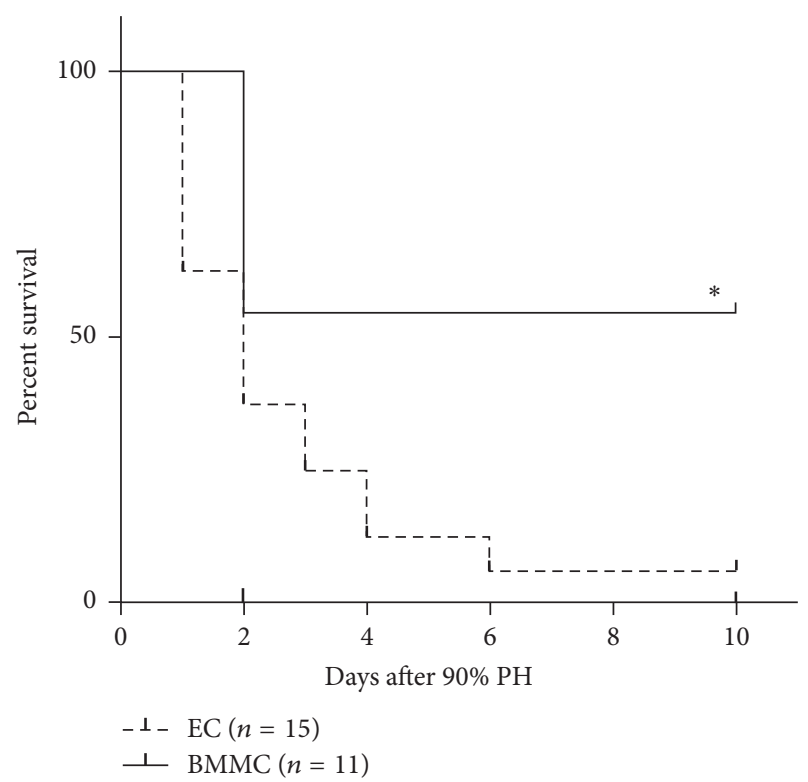

FIGURE 1: Survival rate for 10 days after $90 \%$ partial hepatectomy (PH). BMMC increase survival rate in rats submitted to $\mathrm{PH}\left({ }^{*} \mathrm{P}=\right.$ 0.003, log rank test). EC: empty capsules, BMMC: encapsulated bone marrow mononuclear cells.

rate until 72 hours after $\mathrm{PH}$. Liver size increased over time in both groups and at $72 \mathrm{~h}$ the BMMC group reached $39 \%$ of the original liver weight, whereas EC group reached $46 \%$ (Figure 2(a)). In addition, the number of mitosis (Figure 2(b)) and positive hepatocytes for BrdU (Figures 2(c) and 2(d)) was also similar between groups. Therefore, BMMC do not seem to enhance liver regeneration after $90 \% \mathrm{PH}$.

3.3. BMMC Modulate Cytokines. It is well known that BMM have immunomodulatory properties [17]. Thus, in order to investigate the impact of immunomodulation on survival, we studied serum level of Interleukin-6 (IL-6) and its gene expression in the remnant livers. Serum IL-6 levels were increased in both groups at $6 \mathrm{~h}$ after $90 \% \mathrm{PH}(268 \mathrm{pg} / \mathrm{mL}$ for EC group and $298 \mathrm{pg} / \mathrm{mL}$ for BMMC group, $P=0.9$ ), but it decreased to normal range from $12 \mathrm{~h}$ in both groups equally (see Supplementary Figure 1 of the Supplementary Material available online at https://doi.org/10.1155/2017/5270527). However, in the remnant livers, we observed an increase in Il-6 expression in both groups until 24 hours after 90\% $\mathrm{PH}$ compared to normal values. However, in BMMC group, this increase is lower (5-fold increase) at 6 hours when compared to EC group (25-fold increase, $P=0.03$ ). From $12 \mathrm{~h}$ after $\mathrm{PH}$, the expression in EC group decreased to about 2-fold normal values, whereas in BMMC it remained around 3-6 times higher than normal, albeit this difference is not statistically significant (Figure 3(a)).

On the other hand, for $I L-10$ liver gene expression a diverse outcome was observed. At $6 \mathrm{~h}$ after 90\% PH BMMC group showed near to normal expression values, whereas EC group showed a 12-fold increase compared to normal animals (Figure 3(b), $P<0.001$ comparing BMMC versus 


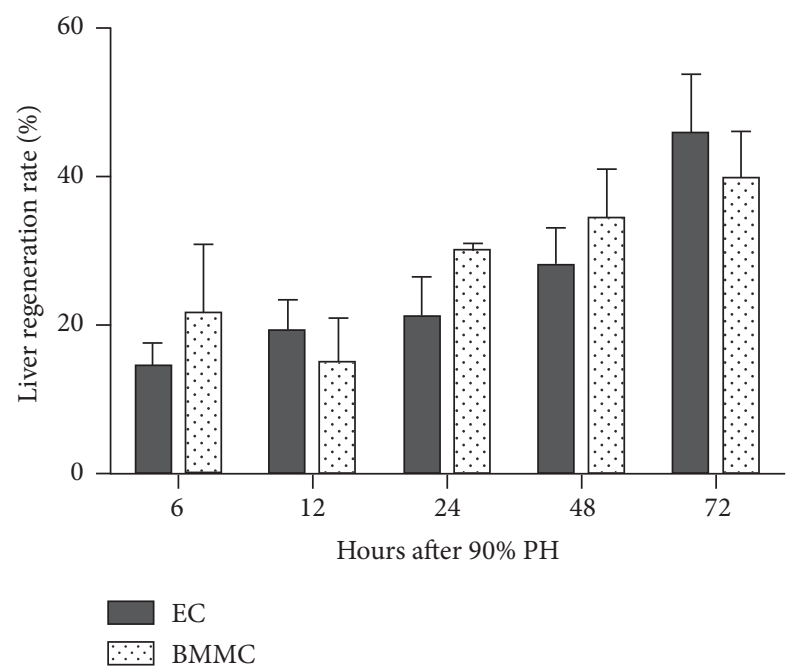

(a)
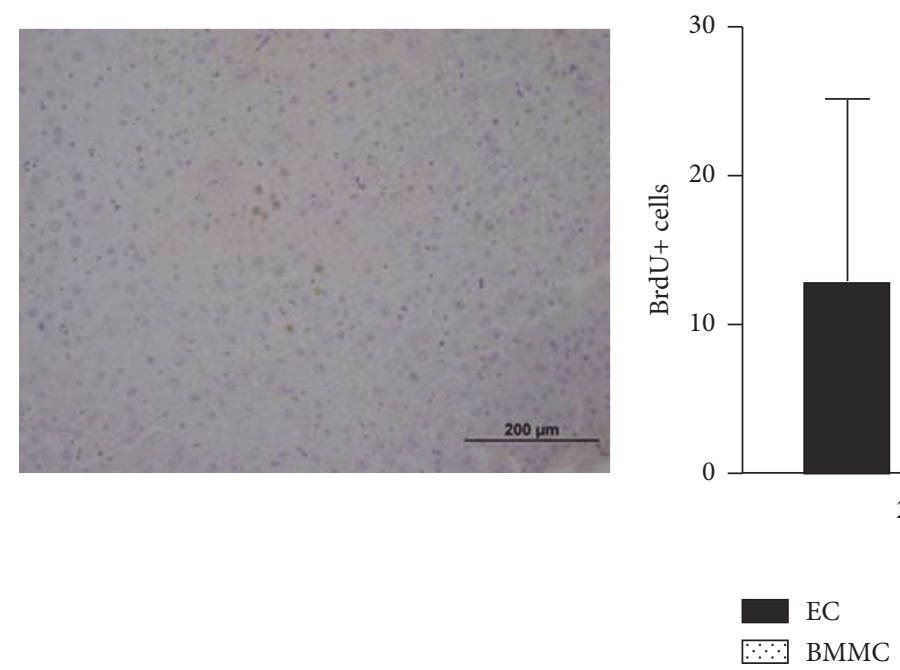

(c)

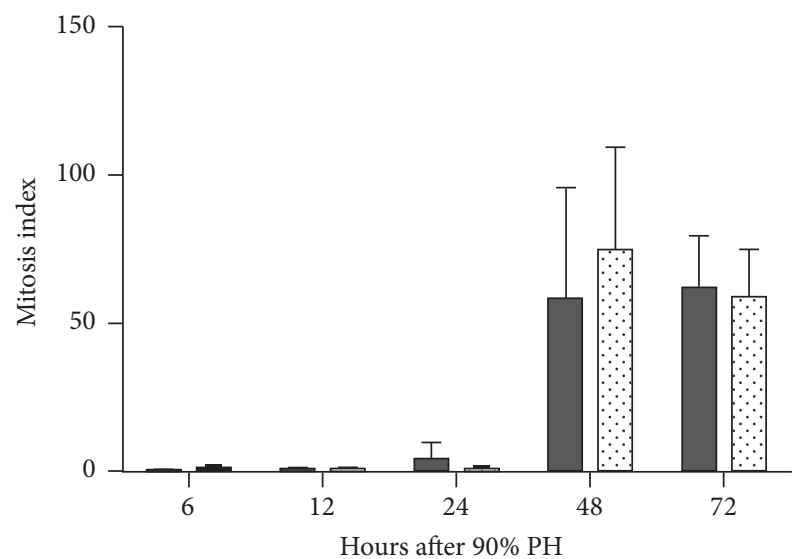

EC

BMMC

(b)

FIgURE 2: (a) Liver regeneration rate at 6, 12, 24, 48, and 72 hours after 90\% partial hepatectomy (PH). (b) Mitotic index at 6, 12, 24, 48, and 72 hours after 90\% PH. (c) BrdU immunohistochemistry, BMMC 48 hours after 90\% partial hepatectomy (20x). (d) Positive hepatocytes for BrdU, EC, and BMMC 24: $12.72 \pm 12.38$ and 5.9 \pm 5.3, respectively; EC and BMMC 48: $10.34 \pm 5.03$ and 9.46 \pm 3.49 , respectively. Values are expressed as means \pm SD. Student's $t$-test. EC: empty capsules, BMMC: encapsulated bone marrow mononuclear cells.

EC groups). In the following hours (12 and $24 \mathrm{~h}$ after $90 \%$ $\mathrm{PH}$ ) BMMC group remains close to normal values, whereas in EC group a sharp reduction in $I L$-10 expression is observed $(P<0.001$ and $P=0.02$, resp. $)$. At 48 and $72 \mathrm{~h}$, though, BMMC show a reduction in expression.

3.4. Cytokine Modulation Is Not Related to the Number of Kupffer Cells. Kupffer cells (KC) are the macrophages resident in the liver and have an essential role in liver injuries by secreting cytokines and priming hepatocytes for division. To address if the expression of cytokines in the liver were was related to the number of $\mathrm{KC}$, we assessed the number of $\mathrm{CD} 68+$ cells in liver sections. We note that in general there is no difference in the amount of $\mathrm{KC}$ cells between the groups except at 12 hours, when BMMC group showed an increase when compared to EC group $(P=0.003$; Figure 4$)$.
3.5. BMMC Benefits Apoptosis. In a previous study [12], we showed that encapsulated whole bone marrow cells increase apoptosis after 90\% PH. Therefore, we analyzed Caspase 3 activity and its expression in the remnant liver. It was observed that BMMC group showed more Caspase 3 activity mainly at 24, 48, and $72 \mathrm{~h}$ after $90 \% \mathrm{PH}(P<0.05$; Figure 5(a)). This result is consistent with the gene expression data, which also was high in BMMC group compared to EC group $(P<0.05$; Figure 5(b)).

\section{Discussion}

The use of BMMC in cell therapy is a suitable approach due to its easy standardized protocol for cell collection and promising benefits in the treatment of liver disease $[5,18]$. However, before this therapy can be widely accepted in the 


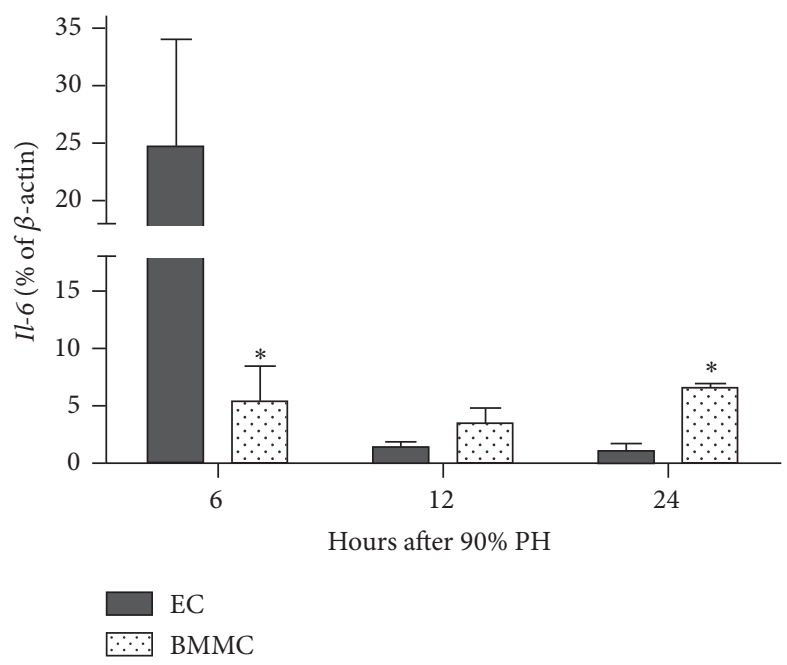

(a)

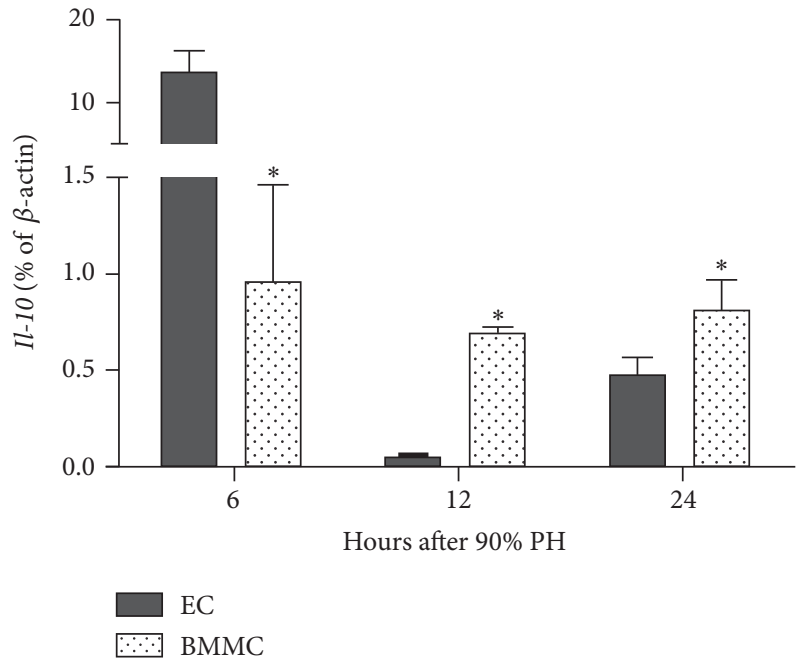

(b)

FigURE 3: BMMC modulate liver cytokines. Liver gene expression of $I l-6$ (a) and $I l-10$ (b) at 6, 12, and 24 hours after $90 \%$ partial hepatectomy $(\mathrm{PH})$. Values are expressed as means $\pm \mathrm{SD}$ in log scale. Student's $t$-test, ${ }^{*} P<0.05$. EC: empty capsules, BMMC: encapsulated bone marrow mononuclear cells.

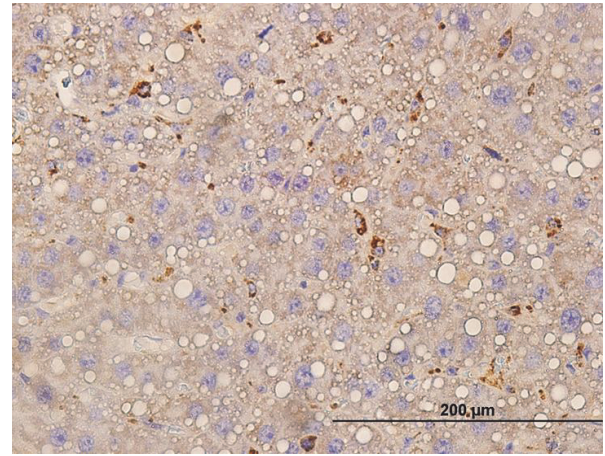

(a)

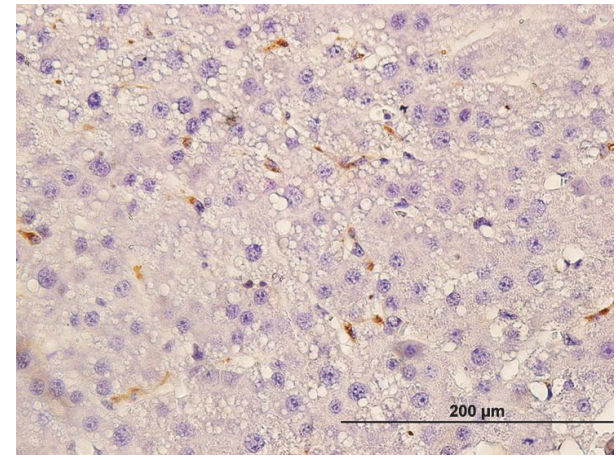

(b)

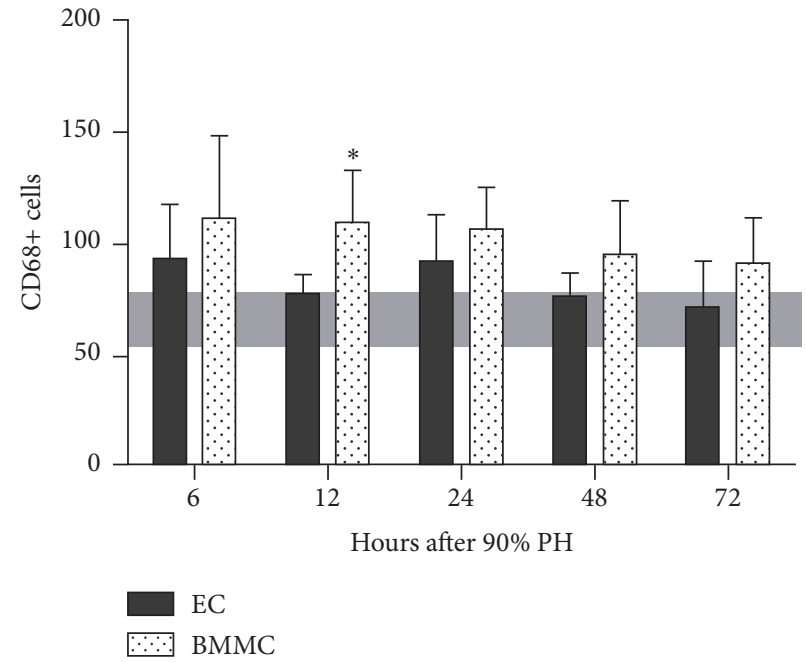

(c)

Figure 4: CD68+ cells in liver sections, EC, and BMMC 72 hours after 90\% partial hepatectomy ((a) and (b), resp.). (c) CD68 + cell quantification at $6,12,24,48$, and 72 hours after $90 \%$ partial hepatectomy (PH). Values are expressed as means \pm SD. Student's $t$-test, ${ }^{*} P=0.003$. EC: empty capsules, BMMC: encapsulated bone marrow mononuclear cells. Horizontal bar indicates normal values. 


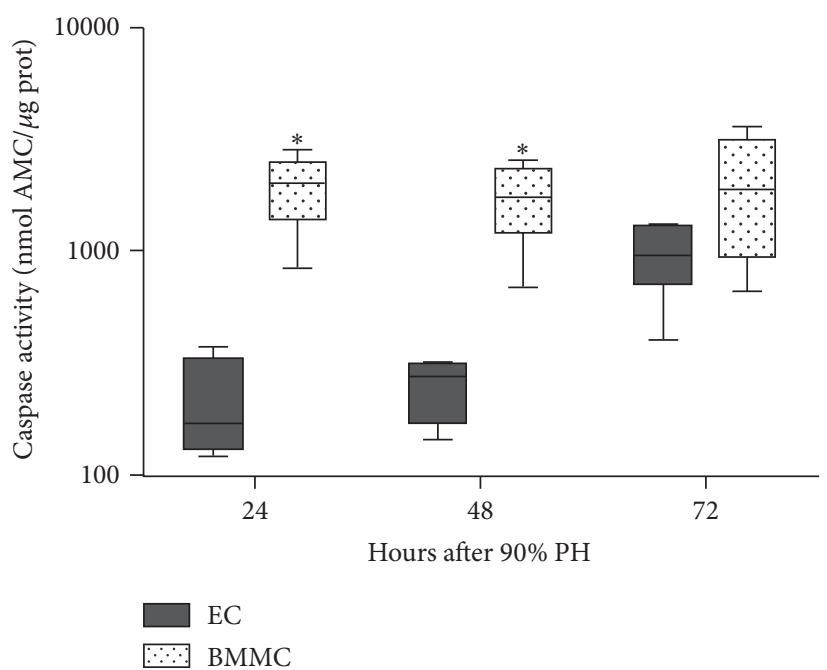

(a)

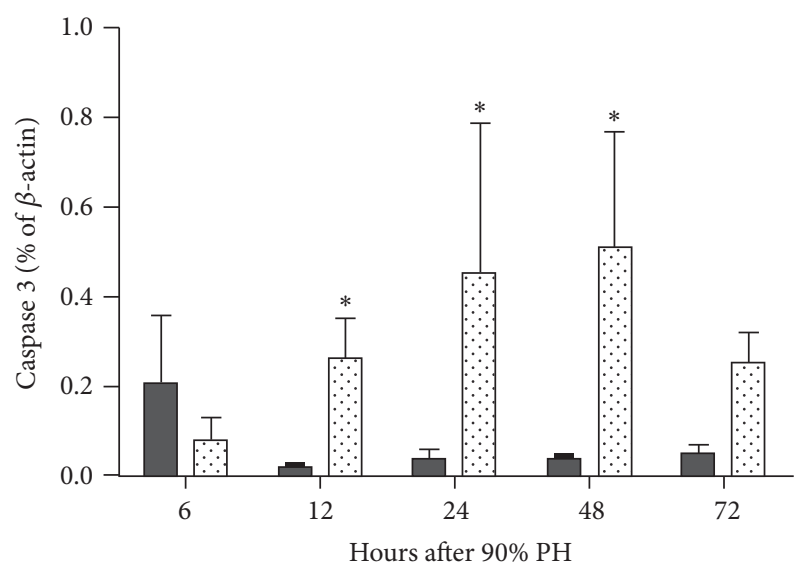

EC BMMC

FIGURE 5: BMMC enhance apoptosis. (a) Caspase 3 activity and (b) liver gene expression of Caspase 3 after $90 \%$ partial hepatectomy. Values are expressed as means \pm SD. Student's $t$-test, ${ }^{*} P<0.05$. EC: empty capsules, BMMC: encapsulated bone marrow mononuclear cells.

clinic, its mechanisms of action must be better elucidated. Several studies have shown that BMMC have immunomodulatory properties [17, 19], focusing the attention of researchers on their paracrine effect [9]. In this sense, the use of microcapsules allows the communication between the cell entrapped within the capsule and the environment where they are implanted without cell-to-cell interaction [20]. In this study we evaluate the paracrine effect of BMMC using semipermeable microcapsules in rats with $90 \% \mathrm{PH}$, a suitable model for analyzing induced acute liver damage $[21,22]$.

The first result of our study showed a marked increase in survival rate in BMMC group which is consistent with other studies of cell therapy for acute liver disease using toxic models $[6,7,23]$. Other studies, using surgical models of 90\% PH, such as Liu and Chang (2006) [24] and Uribe-Cruz et al. (2016) [12], also observed an increase in survival in animals treated with encapsulated cells, but both groups used encapsulated whole bone marrow cells, without separation of mononuclear cells.

In order to study the reasons for increased survival in BMMC group, we analyzed liver regeneration, which is a widely used method to assess recovery after partial hepatectomy $[25,26]$. Liver regeneration rate, assessed either by liver weight, mitotic index, or BrdU, was similar in both groups suggesting that the increase in survival is not related to tissue regeneration. One must note that this is a $90 \%$ partial hepatectomy and not a classical liver regeneration model, such as $70 \% \mathrm{PH}$. So, although liver regeneration is essential for survival, different works point to other factors that influence recovery, including the pace of regeneration [27]. In addition, other studies from our group also point to a positive impact in survival that is not directly linked to hepatocyte regeneration $[12,28]$. Thus, it is suggested that BMMC improve survival through mechanisms other than enhancing hepatocyte proliferation.
Acute liver failure promotes a shock septic response by the immune system [27, 28], leading to a disequilibrium in the levels of pro- and anti-inflammatory cytokines [29]. It is well recognized that IL- 6 and IL-10 have an important role in improving recovery after acute liver failure $[29,30]$. Thus, we analyzed the paracrine effect of BMMC on hepatic gene expression of $\mathrm{Il}-6$ and $\mathrm{Il}-10$ after liver injury. We observed that both experimental groups showed an increase in $\mathrm{Il}-6$ expression at $6 \mathrm{~h}$ after $90 \% \mathrm{PH}$; however in BMMC group this increase was much lower than in EC group. On the other hand, in BMMC-treated animals Il-6 expression remains slightly elevated until $24 \mathrm{~h}$ after $90 \% \mathrm{PH}$. The expression of $\mathrm{Il}-$ 10 in BMMC group was also closer to normal levels, whereas in EC group it was increased at $6 \mathrm{~h}$ and greatly reduced at 12 hours after $90 \% \mathrm{PH}$. It is important to notice that $\mathrm{Il}-6$ is a major inducer of hepatic acute phase response and its expression plays a central role in restoring normal hepatic function following liver injury [31]. On the other hand, $\mathrm{Il}-10$ is a potent anti-inflammatory cytokine and selectively blocks proinflammatory genes in the liver after $\mathrm{PH}$ and reduces the number of macrophages and monocytes in the liver [32]. Moreover, the prevalence of an anti- or proinflammatory response results in the loss of immunohomeostasis and death [33]. So it can be suggested that the effect of BMMC is maintaining the balance between pro- and anti-inflammatory cytokines.

To address if the expression of cytokines in the liver was related to the number of $\mathrm{KC}$, we assessed the number of CD68+ cells in liver sections. Normal Wistar rats have between 50 and 70 CD68+ cells, and this number does not increase significantly after $90 \% \mathrm{PH}$, except at $12 \mathrm{~h}$, when BMMC show an average of 110 CD68+ cells. This lack of statistical difference may be due to the high variability observed among animals in both groups at any time point.

There are some works showing that these cytokines stimulate apoptosis in liver cells [34]. Our results show 
an increase in Caspase 3 activity and gene expression in BMMC group when compared to EC group at 24 and 48 hours. These results are in agreement with the suggestion that apoptosis eliminates unwanted or harmful cells to maintain homeostasis and normal tissue functioning [35]. It is a pathophysiological beneficial process that regulates growth and proliferation, thus ensuring proper organ size and function [36]. We are suggesting that the death of damaged hepatocytes by apoptosis may be a positive effect. There are studies showing that caspases can induce proliferation of neighboring surviving cells to replace dying cells in a process referred to as "apoptosis-induced proliferation" that may be critical for stem cell activity and tissue regeneration [35]. It is possible that such impact on proliferation occurred at later times, that is, after 72 hours, and therefore was not detected in our study. In addition, the death of damaged cells by apoptosis involves less cell leakage and recruitment of inflammatory cells [37] and the therapeutic modulation of apoptosis may represent a valid strategy for the treatment of human liver diseases [38]. Thus, the paracrine effect of BMMC induces Caspase 3, which may result in proper balance between cell death and division during liver regeneration.

\section{Conclusions}

In summary, BMMC regulate immune response and promote apoptosis in the liver after $90 \% \mathrm{PH}$ by paracrine factors. These changes ultimately may be related to the higher survival observed in treated animals. Therefore BMMC are a promising alternative to treat acute liver failure.

\section{Competing Interests}

The authors have no conflict of interests to declare.

\section{Authors' Contributions}

Carlos Oscar Kieling and Carolina Uribe-Cruz contributed equally to this work.

\section{Acknowledgments}

This work was supported by FIPE/HCPA and PRONEX/FAPERGS 10/0039-3.

\section{References}

[1] W. Lee, "Acute liver failure," Seminars in Respiratory and Critical Care Medicine, vol. 33, no. 1, pp. 36-45, 2012.

[2] A. Rutherford and R. T. Chung, "Acute liver failure: mechanisms of hepatocyte injury and regeneration," Seminars in Liver Disease, vol. 28, no. 2, pp. 167-174, 2008.

[3] K. Sun, X. Xie, J. Xie et al., "Cell-based therapy for acute and chronic liver failures: distinct diseases, different choices," Scientific Reports, vol. 4, article 6494, 2014.

[4] S. J. Forbes, S. Gupta, and A. Dhawan, "Cell therapy for liver disease: from liver transplantation to cell factory," Journal of Hepatology, vol. 62, no. 1, pp. S157-S169, 2015.
[5] M. Mohamadnejad, M. Vosough, S. Moossavi et al., "Intraportal infusion of bone marrow mononuclear or CD133+ cells in patients with decompensated cirrhosis: a double-blind randomized controlled trial," Stem Cells Translational Medicine, vol. 5, no. 1, pp. 87-94, 2016.

[6] G. Baldo, R. Giugliani, C. Uribe et al., "Bone marrow mononuclear cell transplantation improves survival and induces hepatocyte proliferation in rats after $\mathrm{CCl}_{4}$ acute liver damage," Digestive Diseases and Sciences, vol. 55, no. 12, pp. 3384-3392, 2010.

[7] M. C. Belardinelli, F. Pereira, G. Baldo et al., "Adult derived mononuclear bone marrow cells improve survival in a model of acetaminophen-induced acute liver failure in rats," Toxicology, vol. 247, no. 1, pp. 1-5, 2008.

[8] C.-H. Park, S. H. Bae, H. Y. Kim et al., "A pilot study of autologous CD34-depleted bone marrow mononuclear cell transplantation via the hepatic artery in five patients with liver failure," Cytotherapy, vol. 15, no. 12, pp. 1571-1579, 2013.

[9] S. Otsuru, P. L. Gordon, K. Shimono et al., "Transplanted bone marrow mononuclear cells and MSCs impart clinical benefit to children with osteogenesis imperfecta through different mechanisms," Blood, vol. 120, no. 9, pp. 1933-1941, 2012.

[10] Y. Yu, J. E. Fisher, J. B. Lillegard, B. Rodysill, B. Amiot, and S. L. Nyberg, "Cell therapies for liver diseases," Liver Transplantation, vol. 18, no. 1, pp. 9-21, 2012.

[11] U. Matte, C. Uribe Cruz, M. L. López, L. Simon, F. Q. Mayer, and R. Giugliani, "Bone marrow-derived mononuclear cells differentiate into hepatocyte-like cells within few Hrs without fusion," Journal of Cell Science \& Therapy, vol. 5, no. 3, article no. 163, 2014.

[12] C. Uribe-Cruz, C. O. Kieling, M. L. López et al., "Encapsulated whole bone marrow cells improve survival in wistar rats after 90\% partial hepatectomy," Stem Cells International, vol. 2016, Article ID 4831524, 9 pages, 2016.

[13] C. O. Kieling, A. N. Backes, R. L. Maurer et al., "The effects of anesthetic regimen in $90 \%$ hepatectomy in rats," Acta Cirurgica Brasileira, vol. 27, no. 10, pp. 702-706, 2012.

[14] J. Gaub and J. Iversen, "Rat liver regeneration after $90 \%$ partial hepatectomy," Hepatology, vol. 4, no. 5, pp. 902-904, 1984.

[15] B. Zhang, M. Inagaki, B. Jiang et al., "Effects of bone marrow and hepatocyte transplantation on liver injury," Journal of Surgical Research, vol. 157, no. 1, pp. 71-80, 2009.

[16] O. H. Lowry, N. J. rosebrough, A. L. Farr, and R. J. Randall, "Protein measurement with the Folin phenol reagent," The Journal of Biological Chemistry, vol. 193, no. 1, pp. 265-275, 1951.

[17] P. Mattar and K. Bieback, "Comparing the immunomodulatory properties of bone marrow, adipose tissue, and birth-associated tissue mesenchymal stromal cells," Frontiers in Immunology, vol. 6, article no. 560, 2015.

[18] T. Itoh and A. Miyajima, "Liver regeneration by stem/progenitor cells," Hepatology, vol. 59, no. 4, pp. 1617-1626, 2014.

[19] T. Yi and S. U. Song, "Immunomodulatory properties of mesenchymal stem cells and their therapeutic applications," Archives of Pharmacal Research, vol. 35, no. 2, pp. 213-221, 2012.

[20] U. Matte, V. L. Lagranha, T. G. De Carvalho, F. Q. Mayer, and R. Giugliani, "Cell microencapsulation: a potential tool for the treatment of neuronopathic lysosomal storage diseases," Journal of Inherited Metabolic Disease, vol. 34, no. 5, pp. 983-990, 2011.

[21] P. N. A. Martins, T. P. Theruvath, and P. Neuhaus, "Rodent models of partial hepatectomies," Liver International, vol. 28, no. 1, pp. 3-11, 2008. 
[22] M.-A. Aller, M. Mendez, M.-P. Nava, L. Lopez, J.-L. A. Arias, and J. Arias, "The value of microsurgery in liver research," Liver International, vol. 29, no. 8, pp. 1132-1140, 2009.

[23] S. Terai, I. Sakaida, H. Nishina, and K. Okita, "Lesson from the GFP/CCl4 model-translational research project: the development of cell therapy using autologous bone marrow cells in patients with liver cirrhosis," Journal of Hepato-BiliaryPancreatic Surgery, vol. 12, no. 3, pp. 203-207, 2005.

[24] Z. C. Liu and M. S. Chang, "Transdifferentiation of bioencapsulated bone marrow cells into hepatocyte-like cells in the $90 \%$ hepatectomized rat model," Liver Transplantation, vol. 12, no. 4 , pp. 566-572, 2006.

[25] H. Amemiya, H. Kono, and H. Fujii, "Liver regeneration is impaired in macrophage colony stimulating factor deficient mice after partial hepatectomy: the role of M-CSF-induced macrophages," Journal of Surgical Research, vol. 165, no. 1, pp. 59-67, 2011.

[26] F. Teixeira-Clerc, M.-P. Belot, S. Manin et al., "Beneficial paracrine effects of cannabinoid receptor 2 on liver injury and regeneration," Hepatology, vol. 52, no. 3, pp. 1046-1059, 2010.

[27] M. Ninomiya, K. Shirabe, T. Terashi et al., "Deceleration of regenerative response improves the outcome of rat with massive hepatectomy," American Journal of Transplantation, vol. 10, no. 7, pp. 1580-1587, 2010.

[28] M. L. López, C. O. Kieling, C. Uribe Cruz et al., "Platelet increases survival in a model of $90 \%$ hepatectomy in rats," Liver International, vol. 34, no. 7, pp. 1049-1056, 2014.

[29] Z. Wu, M. Han, T. Chen, W. Yan, and Q. Ning, "Acute liver failure: mechanisms of immune-mediated liver injury," Liver International, vol. 30, no. 6, pp. 782-794, 2010.

[30] W. Bernal, G. Auzinger, A. Dhawan, and J. Wendon, "Acute liver failure," The Lancet, vol. 376, no. 9736, pp. 190-201, 2010.

[31] D. Schmidt-Arras and S. Rose-John, "IL-6 pathway in the liver: from physiopathology to therapy," Journal of Hepatology, vol. 64, no. 6, pp. 1403-1415, 2016.

[32] M. Wang, X. Zhang, X. I. Xiong et al., "Bone marrow mesenchymal stem cells reverse liver damage in a carbon tetrachlorideinduced mouse model of chronic liver injury," In Vivo (Athens, Greece), vol. 30, no. 3, pp. 187-193, 2016.

[33] C. G. Antoniades, P. A. Berry, J. A. Wendon, and D. Vergani, "The importance of immune dysfunction in determining outcome in acute liver failure," Journal of Hepatology, vol. 49, no. 5, pp. 845-861, 2008.

[34] A. Dangi, C. Huang, A. Tandon, D. Stolz, T. Wu, and C. R. Gandhi, "Endotoxin-stimulated rat hepatic stellate cells induce autophagy in hepatocytes as a survival mechanism," Journal of Cellular Physiology, vol. 231, no. 1, pp. 94-105, 2016.

[35] H. D. Ryoo and A. Bergmann, "The role of apoptosis-induced proliferation for regeneration and cancer," Cold Spring Harbor Perspectives in Biology, vol. 4, no. 8, Article ID a008797, 2012.

[36] K. Wang and B. Lin, "Pathophysiological significance of hepatic apoptosis," ISRN Hepatology, vol. 2013, Article ID 740149, 14 pages, 2013.

[37] S. Elmore, "Apoptosis: a review of programmed cell death," Toxicologic Pathology, vol. 35, no. 4, pp. 495-516, 2007.

[38] M. E. Guicciardi and G. J. Gores, "Apoptosis: a mechanism of acute and chronic liver injury," Gut, vol. 54, no. 7, pp. 1024-1033, 2005. 

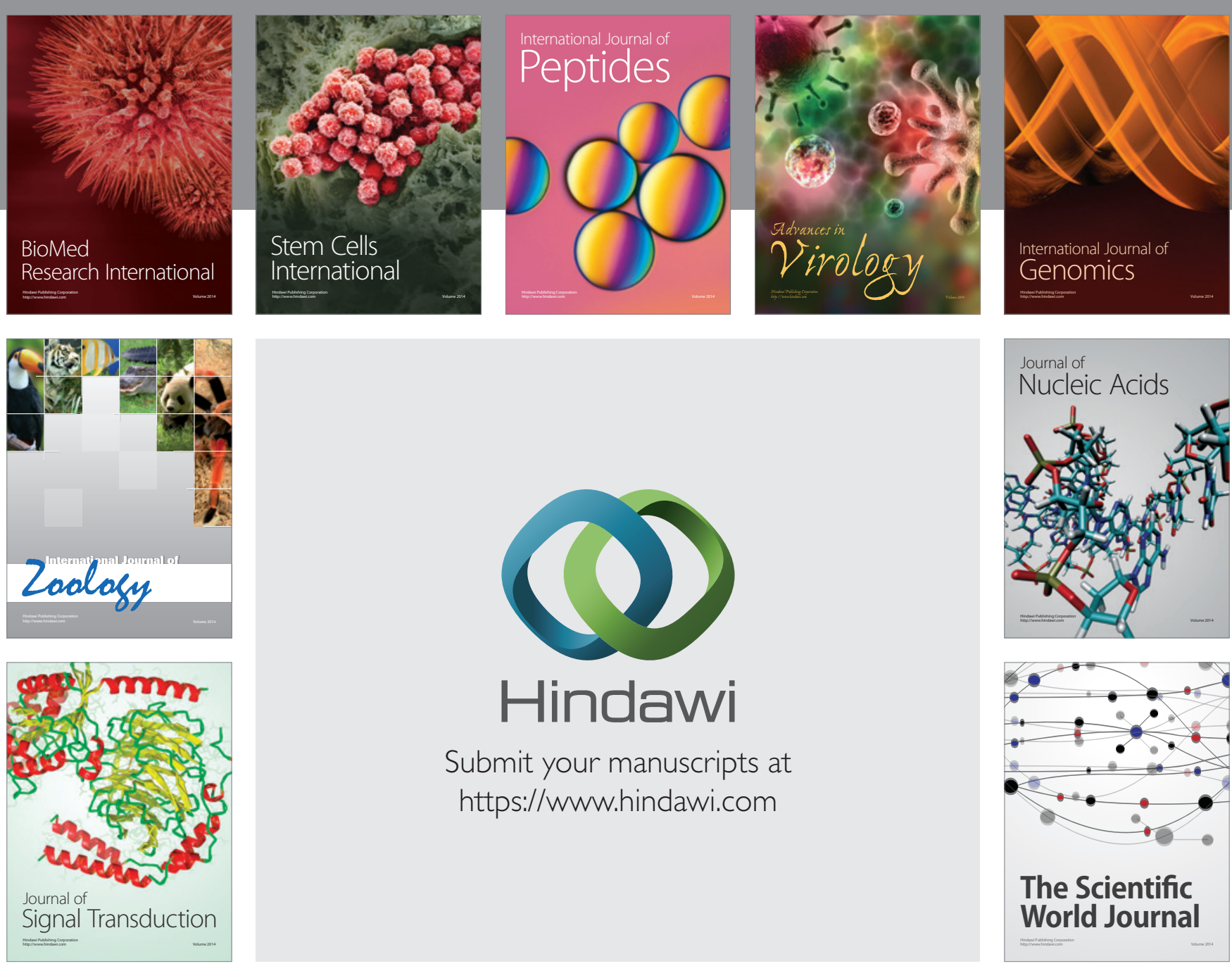

Submit your manuscripts at

https://www.hindawi.com
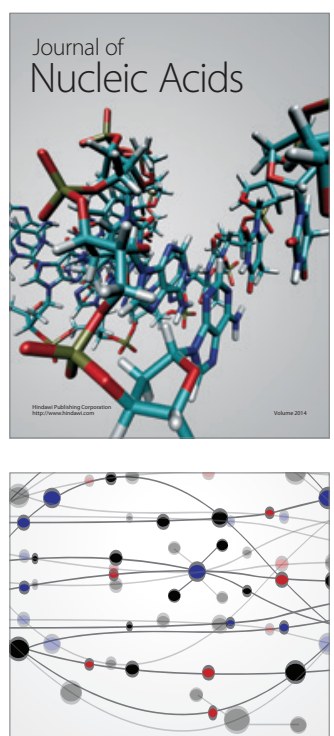

The Scientific World Journal
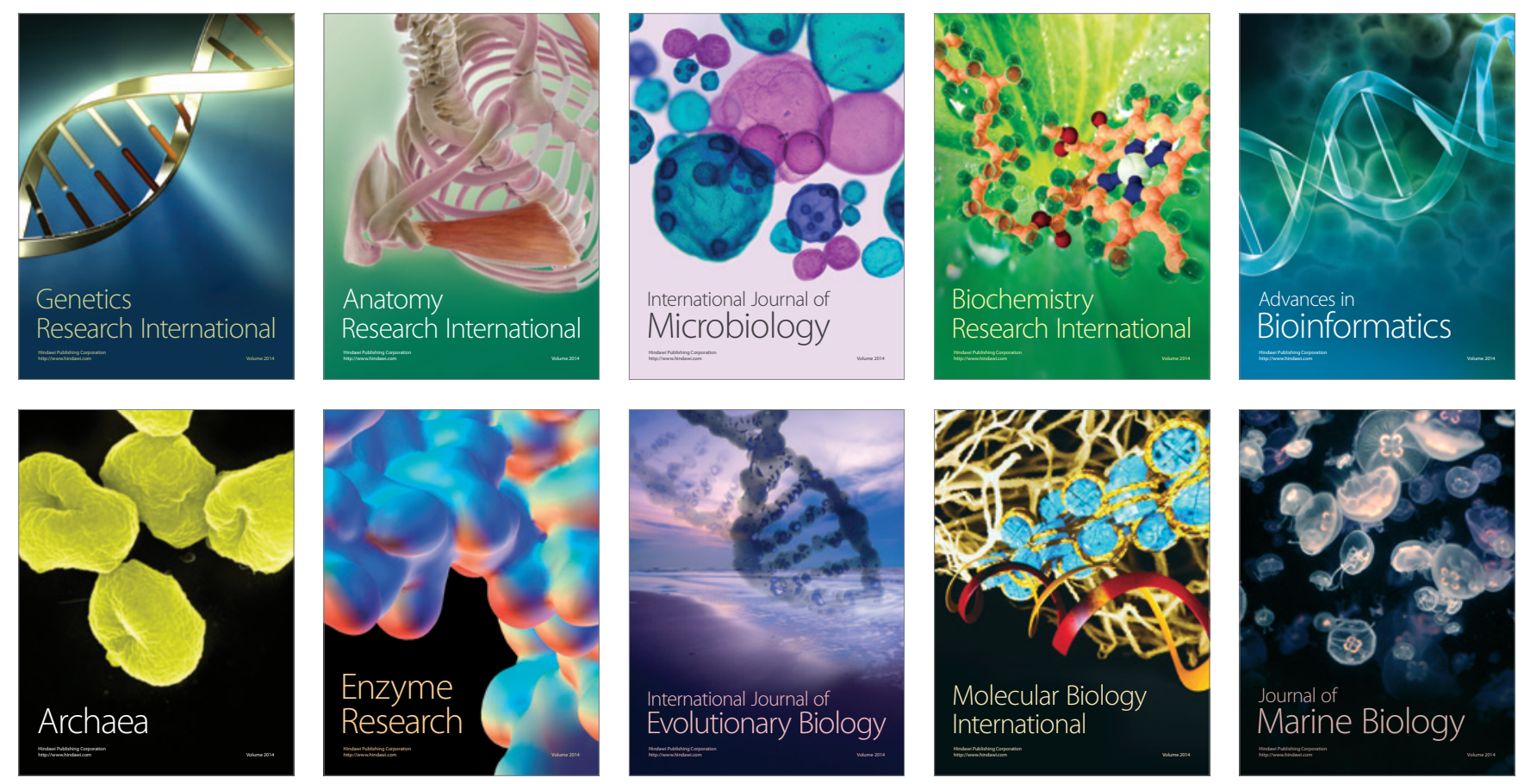